\title{
Fixed point theorems for (L)-type mappings in complete CAT(0) spaces
}

\author{
Jing Zhou ${ }^{a, *}$, Yunan Cuil \\ ${ }^{a}$ Department of Mathematics, Harbin Institute of Technology, Harbin 150080, P. R. China. \\ ${ }^{b}$ Department of Mathematics, Harbin University of Science and Technology, Harbin 150080, P. R. China. \\ Communicated by M. Eslamian
}

\begin{abstract}
In this paper, fixed point properties for a class of more generalized nonexpansive mappings called (L)-type mappings are studied in geodesic spaces. Existence of fixed point theorem, demiclosed principle, common fixed point theorem of single-valued and set-valued are obtained in the third section. Moreover, in the last section, $\Delta$-convergence and strong convergence theorems for (L)-type mappings are proved. Our results extend the fixed point results of Suzuki's results in 2008 and Llorens-Fuster's results in 2011. (C)2017 All rights reserved.
\end{abstract}

Keywords: (L)-type mappings, geodesic spaces, fixed point theorems, common fixed point theorems, three-step iteration scheme.

2010 MSC: 47H09, 47H10, 54E40.

\section{Introduction}

Let $\mathrm{D}$ be a nonempty subset of a metric space $(X, d)$. A mapping $T: D \rightarrow D$ is said to be

1. nonexpansive if $d(T x, T y) \leqslant d(x, y)$ for all $x, y \in D$;

2. quasi-nonexpansive if $d(T x, p) \leqslant d(x, p)$ for all $x \in D$ and $p \in F(T)$, where $F(T)=\{x \in D: T x=x\}$ denotes the set of fixed points of $\mathrm{T}$.

We can find in the literature research about more general classes of mappings than the nonexpansive ones and quasi-nonexpansive ones. For instance, in 2008, Suzuki [28] defined a class of generalized nonexpansive mappings, which he called (C)-type mappings, whose set-valued version was defined and studied in [1, 2, 26, 30]. In 2011, García-Falset et al. [14] introduced two classes of single-valued generalized nonexpansive mappings called $\left(C_{\lambda}\right)$-type mappings and $\left(E_{\mu}\right)$-type mappings, respectively, which both enlarged the family of (C)-type mappings. Again these new classes were generalized to the setvalued case in $[3,9,12,17]$.

Definition 1.1. Let $D$ be a nonempty subset of a metric space $(X, d)$. A mapping $T: D \rightarrow D$ is said to

\footnotetext{
*Corresponding author

Email addresses: zhoujinggirl@126.com (Jing Zhou), cuiya@hrbust.edu.cn (Yunan Cui)
}

doi:10.22436/jnsa.010.03.09 
1. satisfy condition (C), (or be a (C)-type mapping) if

$$
\frac{1}{2} d(x, T x) \leqslant d(x, y) \text { implies } d(T x, T y) \leqslant d(x, y),
$$

for all $x, y \in D$;

2. satisfy condition $\left(C_{\lambda}\right)$, (or be a $\left(C_{\lambda}\right)$-type mapping) if

$$
\lambda d(x, T x) \leqslant d(x, y) \text { implies } d(T x, T y) \leqslant d(x, y),
$$

for all $x, y \in D$ and $\lambda \in(0,1)$;

3. satisfy condition $\left(E_{\mu}\right)$, (or be a $\left(E_{\mu}\right)$-type mapping) if

$$
d(x, T y) \leqslant \mu d(x, T x)+d(x, y),
$$

for all $x, y \in D$ and $\mu \geqslant 1$.

In 2011 [23], fixed point results for a class of single-valued generalized nonexpansive mappings called (L)-type mappings were proved by Llorens-Fuster and Moreno-Gálvez. This class properly contains Suzuki's (C)-type mappings as (1.1) and several of its generalizations such as $\left(C_{\lambda}\right)$-type mappings as (1.2) and $\left(E_{\mu}\right)$-type mappings as (1.3) mentioned before. The set-valued case for (L)-type mappings were discussed in [13] and more results in [24]. Their results closely depend upon geometric characteristics of the Banach space under consideration. In this paper, we shall prove the fixed point property for (L)-type mappings in a metric space without notion of a "topology" and "weak topology".

The aim of this paper is to prove fixed point property for (L)-type mappings in a special kind of metric spaces, namely CAT(0) spaces, which will be defined in the next section. Firstly, we prove the existence theorem of fixed point and demiclosed principle for (L)-type mappings in complete CAT(0) spaces. Furthermore, two common fixed point theorems are also obtained. Finally, we prove that a sequence defined by a three-step iteration $\Delta$-converges (even on some condition strongly converges) to a fixed point of these kind of mappings. Our results extend and improve some results in [23] and [13].

\section{Preliminaries}

Let $(X, d)$ be a metric space and $x, y \in X$ with $d(x, y)=l$. A geodesic path joining $x$ to $y$ is an isometric map $c$ from a closed interval $[0, l] \subset \mathbb{R}$ to $X$ such that $c(0)=x, c(l)=y$. The image of $c$ is called a geodesic (or metric) segment joining $x$ and $y$ denoted by $[x, y]$ whenever it is unique. The space $(X, d)$ is said to be a (uniquely) geodesic space if every two points of $X$ are joined by (exactly) one geodesic segment. A geodesic triangle $\Delta\left(x_{1}, x_{2}, x_{3}\right)$ in a geodesic space $X$ consists of three points $x_{1}, x_{2}, x_{3}$ of $X$ and three geodesic segments joining each pair of vertices. A comparison triangle of a geodesic triangle $\Delta\left(x_{1}, x_{2}, x_{3}\right)$ is the triangle $\bar{\Delta}\left(x_{1}, x_{2}, x_{3}\right):=\Delta\left(\overline{x_{1}}, \overline{x_{2}}, \overline{x_{3}}\right)$ in the Euclidean space $E^{2}$ such that

$$
\mathrm{d}\left(\mathrm{x}_{\mathrm{i}}, \mathrm{x}_{\mathbf{j}}\right)=\mathrm{d}_{\mathrm{E}^{2}}\left(\overline{\mathrm{x}_{i}}, \overline{\mathrm{x}_{\mathbf{j}}}\right), \quad \forall i, j=1,2,3 .
$$

A geodesic space is a CAT(0) space, if for each geodesic triangle $\Delta\left(\mathrm{x}_{1}, \mathrm{x}_{2}, \mathrm{x}_{3}\right)$ in $\mathrm{X}$ and its comparison triangle $\bar{\Delta}:=\Delta\left(\overline{x_{1}}, \overline{x_{2}}, \overline{x_{3}}\right)$ in $E^{2}$, the CAT( 0$)$ inequality

$$
d(x, y) \leqslant d_{E^{2}}(\bar{x}, \bar{y}),
$$

holds for all $x, y \in \Delta$ and $\bar{x}, \bar{y} \in \bar{\Delta}$.

A thorough discussions of these spaces are given in [4]. The following lemma plays an important role in our paper.

Lemma 2.1 ([11]). Let $(\mathrm{X}, \mathrm{d})$ be a CAT(0) space. 
1. For each $x, y \in X$ and $\alpha \in[0,1]$, there exists a unique point $z \in[x, y]$ such that

$$
d(z, x)=\alpha d(x, y), \quad d(z, y)=(1-\alpha) d(x, y) .
$$

Denote $z=(1-\alpha) x \oplus \alpha y$ in the above equations conveniently.

2. For each $x, y, z \in X$ and $\alpha \in[0,1]$, we have

$$
\mathrm{d}((1-\alpha) x \oplus \alpha y, z) \leqslant(1-\alpha) \mathrm{d}(x, z)+\alpha \mathrm{d}(y, z) .
$$

3. For all $\mathrm{t} \in[0,1]$ and $\mathrm{x}, \mathrm{y}, z \in \mathrm{X}$,

$$
d^{2}((1-t) x \oplus t y, z) \leqslant(1-t) d^{2}(x, z)+t d^{2}(y, z)-t(1-t) d^{2}(x, y) .
$$

The inequality (2.1) is also called (CN) inequality. A geodesic space $X$ is a CAT(0) space if and only if $(\mathrm{CN})$ inequality holds.

CAT(0) spaces have a remarkably nice geometric structure. One can see almost immediately from Lemma 2.1 that in such spaces angles exist in a strong sense, the distance function is convex, one has both uniform convexity and orthogonal projection onto convex subsets, etc. Also, because of their generality, CAT(0) spaces arise in a wide variety of contexts. Some examples of CAT(0) spaces are pre-Hilbert spaces (see [4]), R-trees (see [18]), Euclidean buildings (see [6]), the complex Hilbert ball with a hyperbolic metric (see [16]), Hadamard manifolds, and many others.

The following lemma is a consequence of [25, Lemma 2.5].

Lemma 2.2. Let $\left\{x_{n}\right\}$ and $\left\{y_{n}\right\}$ be bounded sequences in a CAT(0) space $X$ and $r \in[0,1)$. Suppose that $x_{n+1}=$ $r y_{n} \oplus(1-r) x_{n}$ and $d\left(y_{n+1}, y_{n}\right) \leqslant d\left(x_{n+1}, x_{n}\right)$ for all $n \in \mathbb{N}$. Then $\lim _{n \rightarrow \infty} d\left(x_{n}, y_{n}\right)=0$. follows.

Firstly the definition of (L)-type mappings in the single-valued case will be given in a metric space as

Definition 2.3. Let D be a nonempty bounded closed convex subset of a CAT(0) space X. A mapping $\mathrm{T}: \mathrm{D} \rightarrow \mathrm{D}$ is said to satisfy condition (L) (or it is an (L)-type mapping) on D provided that it fulfills the following two conditions.

1. If a set $K \subset D$ is nonempty, closed, convex, and $T$-invariant, (i.e., $T(K) \subset K$ ), then there exists an a.f.p.s. for $T$ in $K$ (i.e., $d\left(x_{n}, T x_{n}\right) \rightarrow 0$ for a sequence $\left\{x_{n}\right\}$ in $\left.K\right)$.

2. For any a.f.p.s. $\left\{x_{n}\right\}$ of $T$ in $D$ and each $x \in D$,

$$
\limsup _{n \rightarrow \infty} d\left(x_{n}, T x\right) \leqslant \limsup _{n \rightarrow \infty} d\left(x_{n}, x\right) .
$$

Proposition 2.4. Let $\mathrm{D}$ be a nonempty bounded closed convex subset of a $\mathrm{CAT}(0)$ space $\mathrm{X}$ and $\mathrm{T}: \mathrm{D} \rightarrow \mathrm{D}$ be $a$ mapping satisfying condition $(L)$ with a nonempty fixed point set, then $\mathrm{T}$ is a quasi-nonexpansive mapping.

Proof. Let $p \in F(T)$. Taking $x_{n}=p$ for every positive integer $n$, it is obvious that $\left\{x_{n}\right\}$ is an a.f.p.s. for $T$. From condition (L), we have for each $x \in \mathrm{D}$,

$$
d(p, T x)=\limsup _{n \rightarrow \infty} d\left(x_{n}, T x\right) \leqslant \limsup _{n \rightarrow \infty} d\left(x_{n}, x\right)=d(p, x) .
$$

In other words, $\mathrm{T}$ is a quasi-nonexpansive mapping.

Next, in order to define the set-valued case for (L)-type mappings, we introduce some elementary concepts. Let $\mathrm{D}$ be a nonempty subset of a metric space $X$. We denote by $B(D)$ the collection of all nonempty bounded closed subsets of $D$ and $C(D)$ the collection of all nonempty compact subsets of $D$. Suppose $\mathrm{H}$ is the Hausdorff metric with respect to $d$, that is,

$$
H(U, v):=\max \left\{\sup _{u \in U} \operatorname{dist}(u, V), \sup _{v \in V} \operatorname{dist}(v, U)\right\}, \quad u, v \in B(X),
$$


where dist $(u, V)=\inf _{v \in V} d(u, v)$ is the distance from the point $u$ to the set $V$.

Let $T: X \rightarrow 2^{X}$ be a set-valued mapping. If an element $x \in X$ satisfies $x \in T x$, then $x$ is called a fixed point of $T$. The set of fixed points of $T$ is denoted by $F(T)$. If a sequence $\left\{x_{n}\right\}$ in $D$ satisfies $\operatorname{dist}\left(x_{n}, T x_{n}\right) \rightarrow 0$ as $n \rightarrow \infty$, then $\left\{x_{n}\right\}$ is called an a.f.p.s. for $T$.

Definition 2.5. Let $\mathrm{D}$ be a nonempty bounded closed convex subset of a CAT(0) space $X$. A set-valued mapping $T: D \rightarrow B(D)$ is said to satisfy condition (L), (or it is an (L)-type set-valued mapping), on D provided that it fulfills the following two conditions.

1. If a set $\mathrm{K} \subset \mathrm{D}$ is nonempty, closed, convex, and T-invariant, then there exists an a.f.p.s. for $\mathrm{T}$ in $\mathrm{K}$.

2. For any a.f.p.s. $\left\{x_{n}\right\}$ of $T$ in $D$ and each $x \in D$,

$$
\limsup _{n \rightarrow \infty} \operatorname{dist}\left(x_{n}, T x\right) \leqslant \limsup _{n \rightarrow \infty} d\left(x_{n}, x\right) .
$$

Along with Definition 2.3 and the above two lemmas, we can obtain the following propositions which show the inclusion relations between (L)-type mappings and other generalized nonexpansive mappings in CAT(0) spaces.

Proposition 2.6. Let $\mathrm{D}$ be a nonempty, bounded, and convex subset of a $\mathrm{CAT}(0)$ space $\mathrm{X}$ and $\mathrm{T}: \mathrm{D} \rightarrow \mathrm{D}$ be a mapping satisfying condition (C), then $\mathrm{T}$ satisfies condition (L).

Proof. Recall that if $\mathrm{T}: \mathrm{D} \rightarrow \mathrm{D}$ is a mapping satisfying condition $(\mathrm{C})$, then there exists an a.f.p.s $\left\{x_{n}\right\}$ for $\mathrm{T}$ in $\mathrm{D}$ by [25, Lemma 3.6]. Moreover, in view of [25, Lemma 3.5], we have that, for every $x, y \in D$,

$$
d(x, T y) \leqslant 3 d(T x, x)+d(x, y) .
$$

Hence, for the a.f.p.s. $\left\{x_{n}\right\}$ and each $x \in D$,

$$
\limsup _{n \rightarrow \infty} d\left(x_{n}, T x\right) \leqslant \limsup _{n \rightarrow \infty}\left(3 d\left(x_{n}, T x_{n}\right)+d\left(x_{n}, x\right)\right)=\limsup _{n \rightarrow \infty} d\left(x_{n}, x\right),
$$

which means such mappings satisfy condition (L).

Proposition 2.7. Let $\mathrm{D}$ be a nonempty, bounded, and convex subset of a $\mathrm{CAT}(0)$ space $\mathrm{X}$ and $\mathrm{T}: \mathrm{D} \rightarrow \mathrm{D}$ be $a$ mapping satisfying condition $\left(E_{\mu}\right)$ for some $\mu \geqslant 0$, then $\mathrm{T}$ satisfies condition $(\mathrm{L})$ provided that it satisfies assumption 1 of Definition 2.3.

Proof. Replace 3 with $\mu$ in the proof of Proposition 2.6. Therefore, the desired conclusion is obtained.

Proposition 2.8. Let $\mathrm{D}$ be a nonempty, bounded and convex subset of a CAT(0) space $\mathrm{X}$ and $\mathrm{T}: \mathrm{D} \rightarrow \mathrm{D}$ be $a$ continuous mapping satisfying condition $\left(C_{\lambda}\right)$ for some $\lambda \in(0,1)$, then $T$ satisfies condition $(\mathrm{L})$.

Proof. Define a sequence $\left\{x_{n}\right\}$ in D by taking $x_{1} \in D$ and

$$
x_{n+1}=r T x_{n} \oplus(1-r) x_{n},
$$

for $n \geqslant 1$ and $r \in[\lambda, 1)$. It follows from Lemma 2.1 (1) that

$$
\lambda d\left(x_{n}, T x_{n}\right) \leqslant \operatorname{rd}\left(x_{n}, T x_{n}\right)=d\left(x_{n}, x_{n+1}\right) \text { for all } n \in \mathbb{N} .
$$

By condition $\left(C_{\lambda}\right)$, we have

$$
d\left(T x_{n+1}, T x_{n}\right) \leqslant d\left(x_{n}, x_{n+1}\right) \text { for all } n \in \mathbb{N} .
$$

Hence, $\lim _{n \rightarrow \infty} d\left(x_{n}, T x_{n}\right)=0$ by Lemma 2.2. 
Case 1. If for some $x \in D$, there is a subsequence $\left\{x_{n_{j}}\right\}$ of $\left\{x_{n}\right\}$ converging to $x$. Since $\left\{x_{n_{j}}\right\}$ is an a.f.p.s., then it is obvious that the sequence $\left\{T x_{n_{j}}\right\}$ has the same limit as $\left\{x_{n_{j}}\right\}$, and therefore by the continuity of $\mathrm{T}, \mathrm{x}=\mathrm{T} x$. Thus, for $\left\{x_{n}\right\}$ in $\mathrm{D}$ and $x \in \mathrm{D}$, we have

$$
\limsup _{n \rightarrow \infty} d\left(x_{n}, T x\right) \leqslant \limsup _{n \rightarrow \infty} d\left(x_{n}, x\right)
$$

holds, i.e., T satisfies condition (L).

Case 2. Suppose that for every $x \in D$, the sequence $\left\{x_{n}\right\}$ does not have any subsequence converging to $x$. Noticing that $\left\{x_{n}\right\}$ is an a.f.p.s., for any $\varepsilon>0$, there exists some $n_{0} \in \mathbb{N}$ such that $d\left(x_{n}, T x_{n}\right)<\varepsilon$ for all $n \geqslant n_{0}$. Since $\left\{x_{n}\right\}$ does not converge to $x$, we can put $\varepsilon:=\frac{1}{2} \liminf _{n} d\left(x_{n}, x\right)>0$. Therefore,

$$
\lambda d\left(x_{n}, T x_{n}\right) \leqslant d\left(x_{n}, T x_{n}\right)<\varepsilon<d\left(x_{n}, x\right) .
$$

By condition $\left(C_{\lambda}\right)$, we have

$$
d\left(T x_{n}, T x\right) \leqslant d\left(x_{n}, x\right)
$$

which implies

$$
\limsup _{n \rightarrow \infty} d\left(x_{n}, T x\right) \leqslant \limsup _{n \rightarrow \infty}\left(d\left(x_{n}, T x_{n}\right)+d\left(T x_{n}, T x\right)\right) \leqslant \limsup _{n \rightarrow \infty} d\left(x_{n}, x\right) .
$$

So T satisfies condition (L).

We now give the notion of $\Delta$-convergence and collect some of its basic properties. Let $\left\{x_{n}\right\}$ be a bounded sequence in a $\mathrm{CAT}(0)$ space $X$. For $z \in X$, we set

$$
r\left(z,\left\{x_{n}\right\}\right)=\limsup _{n \rightarrow \infty} d\left(z, x_{n}\right) .
$$

The asymptotic radius $r\left(\left\{x_{n}\right\}\right)$ of $\left\{x_{n}\right\}$ is given by

$$
r\left(\left\{x_{n}\right\}\right)=\inf \left\{r\left(z,\left\{x_{n}\right\}\right): z \in X\right\} .
$$

The asymptotic radius $r_{D}\left(\left\{x_{n}\right\}\right)$ of $\left\{x_{n}\right\}$ with respect to $D \subset X$ is given by

$$
r_{D}\left(\left\{x_{n}\right\}\right)=\inf \left\{r\left(z,\left\{x_{n}\right\}\right): z \in D\right\} .
$$

The asymptotic center $A\left(\left\{x_{n}\right\}\right)$ of $\left\{x_{n}\right\}$ is the set

$$
A\left(\left\{x_{n}\right\}\right)=\left\{z \in X: r\left(z,\left\{x_{n}\right\}\right)=r\left(\left\{x_{n}\right\}\right)\right\} .
$$

And the asymptotic center $A_{D}\left(\left\{x_{n}\right\}\right)$ of $\left\{x_{n}\right\}$ with respect to $D \subset X$ is the set

$$
A_{D}\left(\left\{x_{n}\right\}\right)=\left\{z \in D: r\left(z,\left\{x_{n}\right\}\right)=r\left(\left\{x_{n}\right\}\right)\right\} .
$$

It follows from [10, Proposition 7]) that $A\left(\left\{x_{n}\right\}\right)$ consists of exactly one point in a CAT(0) space. In 1976, Lim [21] introduced the concept of $\Delta$-convergence in a general metric space. In 2008, Kirk and Panyanak [19] brought in $\Delta$-convergence to CAT(0) spaces and proved that there is an analogy between $\Delta$-convergence and weak convergence.

Definition 2.9 ([19]). A sequence $\left\{x_{n}\right\}$ in a CAT(0) space $X$ is said to $\Delta$-converge to $x \in X$ if $x$ is the unique asymptotic center of $\left\{u_{n}\right\}$ for every subsequence $\left\{u_{n}\right\}$ of $\left\{x_{n}\right\}$. In this case, we write $\Delta-\lim _{n \rightarrow \infty} x_{n}=x$ and call $x$ the $\Delta$-limit of $\left\{x_{n}\right\}$.

Lemma 2.10 ([19]). If $\mathrm{D}$ is a closed convex subset of a complete CAT( 0$)$ space and if $\left\{x_{n}\right\}$ is a bounded sequence in $\mathrm{D}$, then the asymptotic centerasymptotic center of $\left\{x_{n}\right\}$ is in D.

Lemma 2.11 ([19]). Every bounded sequence in a complete CAT(0) space always has a $\Delta$-convergent subsequence.

Lemma 2.12 ([11]). If $\left\{x_{n}\right\}$ is a bounded sequence in a complete CAT(0) space with $A\left(\left\{x_{n}\right\}\right)=\{p\},\left\{u_{n}\right\}$ is a subsequence of $\left\{x_{n}\right\}$ with $A\left(\left\{u_{n}\right\}\right)=\{u\}$, and the sequence $\left\{d\left(x_{n}, u\right)\right\}$ is convergent, then $p=u$. 


\section{Fixed point theorems}

Theorem 3.1. Let $\mathrm{D}$ be a nonempty bounded closed convex subset of a complete CAT(0) space X. Suppose T : D $\rightarrow$ $\mathrm{D}$ is a mapping satisfying condition (L). Then $\mathrm{T}$ has a fixed point in $\mathrm{D}$.

Proof. Since T satisfies condition (L), there exists an a.f.p.s. for T in D, say $\left\{x_{n}\right\}$. By Proposition 7 of [10] we let $A\left(\left\{x_{n}\right\}\right)=\{z\}$. It follows from Lemma 2.10 that $z \in D$. By condition (L), we get

$$
\limsup _{n \rightarrow \infty} d\left(x_{n}, T z\right) \leqslant \limsup _{n \rightarrow \infty} d\left(x_{n}, z\right),
$$

which means

$$
r\left(T z,\left\{x_{n}\right\}\right) \leqslant r\left(z,\left\{x_{n}\right\}\right) .
$$

By the uniqueness of asymptotic centers, we have $z=T z$.

Theorem 3.1 extends [23, Theorem 4.2]. By using this theorem along with Proposition 2.4 and [8, Theorem 1.3], we can obtain the following corollary.

Corollary 3.2. Let $\mathrm{D}$ be a nonempty bounded closed convex subset of a complete CAT( 0$)$ space X. Suppose $\mathrm{T}: \mathrm{D} \rightarrow \mathrm{D}$ is a mapping satisfying condition $(\mathrm{L})$. Then $\mathrm{F}(\mathrm{T})$ is nonempty closed, convex and hence contractible.

In 1968, Browder proved demiclosedness principle [5] for nonexpansive mappings which has been one of the fundamental and celebrated results in fixed point theory. Demiclosedness principle states that if $\mathrm{D}$ is a nonempty closed convex subset of a uniformly convex Banach space $X$, and $\mathrm{T}: \mathrm{D} \rightarrow \mathrm{X}$ is a nonexpansive mapping, then $I-T$ is demiclosed at 0 , that is, for any sequence $\left\{x_{n}\right\}$ in $D$, if $\left\{x_{n}\right\}$ weakly converges to $x$ and $(I-T) x_{n}$ strongly converges to 0 , then $x=T x$ (here I is the identity operator of $X$ into itself). The principle is also valid in a space satisfying Opial's condition. It has been known that the demiclosedness principle plays a key role in studying the asymptotic and ergodic behavior of nonexpansive mapping, see for example [15, 22].

Remark 3.3. Let D be a closed convex subset of a CAT(0) space $X$ and $\left\{x_{n}\right\}$ be a bounded sequence in D. We need the following notation:

$$
\left\{x_{n}\right\} \rightarrow \omega \quad \text { if and only if } \Phi(\omega)=\inf _{x \in C} \Phi(x),
$$

where $\Phi(x):=\limsup _{n \rightarrow \infty} d\left(x_{n}, x\right)$.

Theorem 3.4 in the following takes use of the notion defined above to prove demiclosedness principle for (L)-type mappings which extend [23, Theorem 4.6] to CAT(0) spaces.

Theorem 3.4 (Demiclosed principle). Suppose $\mathrm{D}$ is a bounded closed convex subset of a complete CAT(0) space $\mathrm{X}$ and $\mathrm{T}: \mathrm{D} \rightarrow \mathrm{D}$ is a mapping satisfying condition (L). If $\left\{\mathrm{x}_{\mathrm{n}}\right\} \subset \mathrm{D}$ is an a.f.p.s. for $\mathrm{T}$ such that $\left\{\mathrm{x}_{\mathrm{n}}\right\} \rightarrow \mathrm{p}$, then $\mathrm{T} p=p$.

Proof. By the definition, $\left\{x_{n}\right\} \rightarrow p$ if and only if $A_{D}\left(\left\{x_{n}\right\}\right)=\{p\}$. We have $A\left(\left\{x_{n}\right\}\right)=\{p\}$ from Lemma 2.10 and Lemma 2.11. Since $\left\{x_{n}\right\}$ is an a.f.p.s. for T, we have

$$
\Phi(x):=\limsup _{n \rightarrow \infty} d\left(x_{n}, x\right)=\limsup _{n \rightarrow \infty} d\left(T x_{n}, x\right) .
$$

Taking $x=T p$ in (3.1), we have

$$
\Phi(T p)=\limsup _{n \rightarrow \infty} d\left(x_{n}, T p\right) \leqslant \limsup _{n \rightarrow \infty} d\left(x_{n}, p\right)=\Phi(p) .
$$

Furthermore, for any $n \geqslant 1$, it follows from $(\mathrm{CN})$ inequality with $t=\frac{1}{2}$ that

$$
d^{2}\left(x_{n}, \frac{p \oplus T p}{2}\right) \leqslant \frac{1}{2} d^{2}\left(x_{n}, p\right)+\frac{1}{2} d^{2}\left(x_{n}, T p\right)-\frac{1}{4} d^{2}(p, T p) .
$$


Letting $n \rightarrow \infty$ and taking superior limit on the both sides of the above inequality, we get

$$
\Phi\left(\frac{p \oplus T p}{2}\right) \leqslant \frac{1}{2} \Phi(p)+\frac{1}{2} \Phi(T p)-\frac{1}{4} d^{2}(p, T p) .
$$

Since $A\left(\left\{x_{n}\right\}\right)=\{p\}$, we have

$$
\Phi(p) \leqslant \Phi\left(\frac{p \oplus T p}{2}\right) \leqslant \frac{1}{2} \Phi(p)+\frac{1}{2} \Phi(T p)-\frac{1}{4} d^{2}(p, T p),
$$

which implies that

$$
d(p, T p)=0
$$

i.e., $p=T p$.

Lemma 3.5 (cf. [20, 27]). Let X be a complete CAT(0) space, then the intersection of any decreasing sequence of nonempty bounded closed convex subsets of $\mathrm{X}$ is nonempty.

Together with Theorem 3.1 and Lemma 3.5, we have a common fixed point theorem of a countable family of mappings which satisfy condition (L).

Theorem 3.6. Let $\mathrm{D}$ be a nonempty bounded closed and convex subset of a complete $\mathrm{CAT}(0)$ space $\mathrm{X}$. Let $\left\{\mathrm{T}_{i}\right\}_{i=1}^{\infty}$ be a countable family of commuting mappings on $\mathrm{D}$ satisfying condition (L). Then $\left\{\mathrm{T}_{i}\right\}_{i=1}^{\infty}$ has a common fixed point.

Proof. Let $C_{n}:=\bigcap_{i=1}^{n} F\left(T_{i}\right)$ for each $n$. From Corollary 3.2, $C_{1}=F\left(T_{1}\right)$ is nonempty bounded closed and convex subset of $X$. Now we assume that $C_{k-1}$ is nonempty bounded closed and convex for $k \in \mathbb{N}$. We are going to show that $C_{k}$ is also nonempty bounded closed and convex. Let $p \in C_{k-1}$ and $i \in \mathbb{N}$ with $1 \leqslant i<k$. Since $T_{k}$ and $T_{i}$ commute, we have

$$
\mathrm{T}_{k} p=\mathrm{T}_{k} \circ \mathrm{T}_{i} \mathrm{p}=\mathrm{T}_{i} \circ \mathrm{T}_{k} \mathrm{p} .
$$

Thus $T_{k} p$ is a fixed point of $T_{i}$, which implies that $T_{k} p \in C_{k-1}$. Hence we get $T_{k}\left(C_{k-1}\right) \subset C_{k-1}$. By Theorem 3.1, $T_{k}$ has a fixed point in $C_{k-1}$, that is,

$$
\mathrm{C}_{\mathrm{k}}=\mathrm{C}_{\mathrm{k}-1} \bigcap \mathrm{F}\left(\mathrm{T}_{\mathrm{k}}\right) \neq \emptyset \text {. }
$$

Also, it is closed and convex by Corollary 3.2. By induction, $C_{n}$ is nonempty bounded closed and convex for all $n \in \mathbb{N}$. Since $C_{n} \subset C_{n-1}$ for all $n \in \mathbb{N}$, by Lemma 3.5 we have

$$
\bigcap_{i=1}^{\infty} F\left(T_{i}\right)=\bigcap_{n=1}^{\infty} C_{n} \neq \emptyset .
$$

This completes the proof.

Theorem 3.7. Let $\mathrm{t}: \mathrm{D} \rightarrow \mathrm{D}$ and $\mathrm{T}: \mathrm{D} \rightarrow \mathrm{C}(\mathrm{D})$ be a single-valued mapping and a set-valued mapping, respectively. If both $\mathrm{t}$ and $\mathrm{T}$ satisfy the condition $(\mathrm{L})$ and in the meantime, they have common a.f.p.s., then they have a common fixed point, that is, there exists a point $z \in \mathrm{D}$ such that $z=\mathrm{t} z \in \mathrm{T} z$.

Proof. By Theorem 3.1 and Corollary 3.2, we know that the mapping $t$ has a fixed point set $F(t)$ which is a nonempty closed convex subset of $X$. Let $p \in F(t)$. Since $T p$ is a bounded closed convex subset of $X$, we can obtain that $t$ has a fixed point in $T p$ for $p \in F(t)$. From the assumption, let $\left\{u_{n}\right\}$ be the common a.f.p.s. and $A\left(\left\{u_{n}\right\}\right)=\{z\}$. By the proof of Theorem 3.1, we have that $z \in F(t)$. Since $T z$ is a compact set, there exists $v_{n} \in \mathrm{T} z$ such that

$$
d\left(u_{n}, v_{n}\right)=\operatorname{dist}\left(u_{n}, T z\right) .
$$

Again from the compactness of $T z$, we may assume that $v_{n} \rightarrow z^{\prime} \in \mathrm{T} z$. Since $T$ satisfies condition (L),

$$
\limsup _{n \rightarrow \infty} d\left(u_{n}, z^{\prime}\right) \leqslant \limsup _{n \rightarrow \infty} d\left(u_{n}, v_{n}\right)+\limsup _{n \rightarrow \infty} d\left(v_{n}, z^{\prime}\right)=\limsup _{n \rightarrow \infty} \operatorname{dist}\left(u_{n}, T z\right) \leqslant \limsup _{n \rightarrow \infty} \operatorname{dist}\left(u_{n}, z\right) \text {. }
$$

This implies that

$$
r\left(z^{\prime},\left\{u_{n}\right\}\right) \leqslant r\left(z,\left\{u_{n}\right\}\right) .
$$

By the uniqueness of asymptotic centers, we have $z=z^{\prime} \in \mathrm{T} z$. Hence $z=\mathrm{t} z \in \mathrm{T} z$. 


\section{Convergence theorems}

In this section, we shall prove $\Delta$ and strong convergence theorems for (L)-type mappings of a threestep iteration scheme introduced by Thakur et al. in [29] which not only converges faster than the known iterations but also is stable. Give $x_{1} \in D$, the sequence $\left\{x_{n}\right\}$ is generated by

$$
\left\{\begin{array}{l}
x_{1} \in D \\
x_{n+1}=T y_{n}, \\
y_{n}=T\left(\left(1-\alpha_{n}\right) x_{n} \oplus \alpha_{n} z_{n}\right), \\
z_{n}=\left(1-\beta_{n}\right) x_{n} \oplus \beta_{n} T x_{n},
\end{array}\right.
$$

for all $n \geqslant 1$, where $\left\{\alpha_{n}\right\}$ and $\left\{\beta_{n}\right\}$ are real sequences with $0<a \leqslant \alpha_{n}, \beta_{n} \leqslant b<1$.

We now establish the following useful lemma.

Lemma 4.1. Let $\mathrm{D}$ be a nonempty bounded closed convex subset of a complete $\mathrm{CAT}(0)$ space $\mathrm{X}$ and let $\mathrm{T}: \mathrm{D} \rightarrow \mathrm{D}$ be a mapping satisfying condition (L). For arbitrary chosen $x_{1} \in D$ and $\left\{x_{n}\right\}$ generated by (4.1), $\lim _{n \rightarrow \infty} d\left(x_{n}, p\right)$ exists for all $\mathrm{p} \in \mathrm{F}(\mathrm{T})$.

Proof. By Theorem 3.1, $\mathrm{F}(\mathrm{T})$ is nonempty. Given $p \in \mathrm{F}(\mathrm{T})$, by Lemma 2.1 (2) and Proposition 2.4 we have

$$
\begin{aligned}
d\left(z_{n}, p\right) & \left.=d\left(\left(1-\beta_{n}\right) x_{n} \oplus \beta_{n} T x_{n}, p\right)\right) \\
& \leqslant\left(1-\beta_{n}\right) d\left(x_{n}, p\right)+\beta_{n} d\left(T x_{n}, p\right) \\
& \leqslant\left(1-\beta_{n}\right) d\left(x_{n}, p\right)+\beta_{n} d\left(x_{n}, T p\right) \\
& \leqslant\left(1-\beta_{n}\right) d\left(x_{n}, p\right)+\beta_{n} d\left(x_{n}, p\right) \\
& =d\left(x_{n}, p\right)
\end{aligned}
$$

and from (4.2),

$$
\begin{aligned}
d\left(y_{n}, p\right) & =d\left(T\left(\left(1-\alpha_{n}\right) x_{n} \oplus \alpha_{n} z_{n}\right), p\right) \\
& \left.\leqslant d\left(\left(1-\alpha_{n}\right) x_{n} \oplus \alpha_{n} z_{n}\right), p\right) \\
& \leqslant\left(1-\alpha_{n}\right) d\left(x_{n}, p\right)+\alpha_{n} d\left(z_{n}, p\right) \\
& \leqslant\left(1-\alpha_{n}\right) d\left(x_{n}, p\right)+\alpha_{n} d\left(x_{n}, p\right) \\
& =d\left(x_{n}, p\right) .
\end{aligned}
$$

By (4.3) we can obtain that

$$
d\left(x_{n+1}, p\right)=d\left(T y_{n}, p\right) \leqslant d\left(y_{n}, p\right) \leqslant d\left(x_{n}, p\right) .
$$

Thus, $\left\{d\left(x_{n}, p\right)\right\}$ is bounded and decreasing for all $p \in F(T)$, i.e., $\lim _{n \rightarrow \infty} d\left(x_{n}, p\right)$ exists.

Lemma 4.2 ([7, Lemma 3.2]). Let $\mathrm{X}$ be a CAT(0) space, $\mathrm{x} \in \mathrm{X}$ be a given point, and $\left\{\mathrm{t}_{\mathrm{n}}\right\}$ be a sequence in $[\mathrm{a}, \mathrm{b}]$ for some $\mathrm{a}, \mathrm{b} \in(0,1)$. If $\left\{\mathrm{x}_{\mathrm{n}}\right\}$ and $\left\{\mathrm{y}_{\mathrm{n}}\right\}$ are sequences in $\mathrm{X}$ such that

$$
\limsup _{n \rightarrow \infty} d\left(x_{n}, x\right) \leqslant r, \quad \limsup _{n \rightarrow \infty} d\left(y_{n}, x\right) \leqslant r, \quad \text { and } \lim _{n \rightarrow \infty} d\left(\left(1-t_{n}\right) x_{n} \oplus t_{n} y_{n}, x\right)=r,
$$

for some $r \geqslant 0$. Then

$$
\lim _{n \rightarrow \infty} d\left(x_{n}, y_{n}\right)=0
$$

Theorem 4.3. Let $\mathrm{D}$ be a nonempty bounded closed convex subset of a complete CAT(0) space X. Suppose $\mathrm{T}: \mathrm{D} \rightarrow$ $\mathrm{D}$ is a mapping satisfying condition (L). For arbitrary chosen $\mathrm{x}_{1} \in \mathrm{D}$ and $\left\{\mathrm{x}_{\mathrm{n}}\right\}$ generated by $(4.1),\left\{\mathrm{x}_{\mathrm{n}}\right\} \Delta$-converges to a fixed point of $\mathrm{T}$. 
Proof. First we prove that

$$
\lim _{n \rightarrow \infty} d\left(x_{n}, T x_{n}\right)=0 .
$$

In fact, it follows from Lemma 4.1 that for each given $p \in F(T), \lim _{n \rightarrow \infty} d\left(x_{n}, p\right)$ exists, without loss of generality, let

$$
\lim _{n \rightarrow \infty} d\left(x_{n}, p\right)=r \geqslant 0
$$

By Proposition 2.4, we have

$$
\limsup _{n \rightarrow \infty} d\left(T x_{n}, p\right) \leqslant \limsup _{n \rightarrow \infty} d\left(x_{n}, p\right)=r .
$$

Since $\left\{\alpha_{n}\right\}$ is a sequence with $0<a \leqslant \alpha_{n} \leqslant b<1$, we can assume that $\lim _{n \rightarrow \infty} \alpha_{n}=\alpha \in[a, b]$. By using (4.3)-(4.5), we get

$$
\begin{aligned}
r=\lim _{n \rightarrow \infty} d\left(x_{n+1}, p\right) & =\lim _{n \rightarrow \infty} d\left(T y_{n}, p\right) \\
& \left.\leqslant \lim _{n \rightarrow \infty} d\left(\left(1-\alpha_{n}\right) x_{n} \oplus \alpha_{n} z_{n}\right), p\right) \\
& \leqslant \lim _{n \rightarrow \infty}\left(1-\alpha_{n}\right) d\left(x_{n}, p\right)+\lim _{n \rightarrow \infty} \alpha_{n} d\left(z_{n}, p\right) \\
& =(1-\alpha) r+\alpha \lim _{n \rightarrow \infty} d\left(z_{n}, p\right),
\end{aligned}
$$

which implies that

$$
\lim _{n \rightarrow \infty} d\left(z_{n}, p\right) \geqslant r .
$$

On the other hand, it follows from (4.2) and (4.5) that

$$
\lim _{n \rightarrow \infty} d\left(z_{n}, p\right) \leqslant \lim _{n \rightarrow \infty} d\left(x_{n}, p\right)=r .
$$

Hence, together with (4.7) and (4.8), we have

$$
r \leqslant \lim _{n \rightarrow \infty} d\left(z_{n}, p\right)=\lim _{n \rightarrow \infty} d\left(\left(1-\beta_{n}\right) x_{n} \oplus \beta_{n} T x_{n}, p\right) \leqslant r,
$$

which implies that

$$
\lim _{n \rightarrow \infty} d\left(\left(1-\beta_{n}\right) x_{n} \oplus \beta_{n} T x_{n}, p\right)=r,
$$

where $0<a \leqslant \beta_{n} \leqslant b<1$. By (4.5), (4.6), (4.9), as well as Lemma 4.2, it gets that

$$
\lim _{n \rightarrow \infty} d\left(x_{n}, T x_{n}\right)=0,
$$

i.e., $\left\{x_{n}\right\}$ is an a.f.p.s. of $T$ in D.

Now we prove that

$$
\omega_{w}\left(x_{n}\right):=\bigcup_{\left\{u_{n}\right\} \subset\left\{x_{n}\right\}} A\left(\left\{u_{n}\right\}\right) \subset F(T),
$$

and $\omega_{w}\left(x_{n}\right)$ consists of exactly one point.

In fact, $u \in \omega_{w}\left(x_{n}\right)$, then, there exists a subsequence $\left\{u_{n}\right\}$ of $\left\{x_{n}\right\}$ such that $A\left(\left\{u_{n}\right\}\right)=\{u\}$. By Lemma 2.10 and Lemma 2.11, there exists a subsequence $\left\{v_{n}\right\}$ of $\left\{u_{n}\right\}$ such that $\Delta-\lim _{n \rightarrow \infty} v_{n}=v \in D$. In view of (4.10) and Theorem 3.4, we have $v \in F(T)$. Furthermore, $u=v$ by Lemma 2.12. This implies that $\omega_{w}\left(x_{n}\right) \subset F(T)$. Next we claim that $\omega_{w}\left(x_{n}\right)$ consists of exactly one point. Let $\left\{u_{n}\right\}$ be a subsequence of $\left\{x_{n}\right\}$ with $A\left(\left\{u_{n}\right\}\right)=\{u\}$ and let $A\left(\left\{x_{n}\right\}\right)=\{x\}$. Since $u \in \omega_{w}\left(x_{n}\right) \subset F(T)$, from Lemma 4.1 we know that $\left\{d\left(x_{n}, \mathfrak{u}\right)\right\}$ is convergent. In view of Lemma 2.12, we have $x=\mathfrak{u}$.

Finally we prove that $\left\{x_{n}\right\} \Delta$-converges to a fixed point of $T$.

In fact, by Lemma 4.1 we know that $\left\{d\left(x_{n}, p\right)\right\}$ is convergent for each $p \in F(T)$. By (4.10), $\lim _{n \rightarrow \infty} d\left(x_{n}\right.$, $\left.T x_{n}\right)=0$. By $(4.11), \omega_{w}\left(x_{n}\right) \subset F(T)$ and $\omega_{w}\left(x_{n}\right)$ consists of exactly one point. This shows that $\left\{x_{n}\right\} \Delta$ converges to a point of $\mathrm{F}(\mathrm{T})$. This completes the proof. 
Theorem 4.4. Suppose that $\mathrm{X}, \mathrm{T},\left\{\mathrm{x}_{\mathrm{n}}\right\}$ are as in Theorem 4.3 and $\mathrm{D}$ is a nonempty bounded closed convex compact subset of $X$. Then $\left\{x_{n}\right\}$ strongly converges to a fixed point of $T$.

Proof. In view of the proof of Theorem 4.3, we have $\lim _{n \rightarrow \infty} d\left(x_{n}, T x_{n}\right)=0$. Since D is compact, there exists a subsequence $\left\{x_{n_{k}}\right\}$ of $\left\{x_{n}\right\}$ such that $\left\{x_{n_{k}}\right\}$ strongly converges to some $z \in D$. By condition (L), we have

$$
\limsup _{k \rightarrow \infty} d\left(x_{n_{k}}, T z\right) \leqslant \limsup _{k \rightarrow \infty} d\left(x_{n_{k}}, z\right) \text { for all } k \in \mathbb{N} \text {. }
$$

Thus we have $\left\{x_{n_{k}}\right\}$ converges to Tz. This implies $z=T z$, i.e., $z \in F(T)$. By Lemma 4.1, we have $\lim _{n \rightarrow \infty} d\left(x_{n}, z\right)$ exists, thus $z$ is the strong limit of the sequence $\left\{x_{n}\right\}$ itself.

\section{Acknowledgment}

The authors would like to appreciate the anonymous referee for some valuable comments and useful suggestions. Besides, the paper is supported by NFS of HeiLongjiang Provience (A2015018).

\section{References}

[1] A. Abkar, M. Eslamian, Fixed point theorems for Suzuki generalized nonexpansive multivalued mappings in Banach spaces, Fixed Point Theory Appl., 2010 (2010), 10 pages. 1

[2] A. Abkar, M. Eslamian, A fixed point theorem for generalized nonexpansive multivalued mappings, Fixed Point Theory, 12 (2011), 241-246. 1

[3] A. Abkar, M. Eslamian, Generalized nonexpansive multivalued mappings in strictly convex Banach spaces, Fixed Point Theory, 14 (2013), 269-280. 1

[4] M. R. Bridson, A. Haefliger, Metric spaces of non-positive curvature, Grundlehren der Mathematischen Wissenschaften [Fundamental Principles of Mathematical Sciences], Springer-Verlag, Berlin, (1999). 2, 2

[5] F. E. Browder, Semicontractive and semiaccretive nonlinear mappings in Banach spaces, Bull. Amer. Math. Soc., 74 (1968), 660-665. 3

[6] K. S. Brown, Buildings, Springer-Verlag, New York, (1989). 2

[7] S. S. Chang, L. Wang, H. W. J. Lee, C. K. Chan, L. Yang, Demiclosed principle and $\Delta$-convergence theorems for total asymptotically nonexpansive mappings in CAT(0) spaces, Appl. Math. Comput., 219 (2012), 2611-2617. 4.2

[8] P. Chaoha, A. Phon-on, A note on fixed point sets in CAT(0) spaces, J. Math. Anal. Appl., 320 (2006), 983-987. 3

[9] S. Dhompongsa, A. Kaewcharoen, Fixed point theorems for nonexpansive mappings and Suzuki-generalized nonexpansive mappings on a Banach lattice, Nonlinear Anal., 71 (2009), 5344-5353. 1

[10] S. Dhompongsa, W. A. Kirk, B. Sims, Fixed points of uniformly Lipschitzian mappings, Nonlinear Anal., 65 (2006), 762-772. 2, 3

[11] S. Dhompongsa, B. Panyanak, On $\Delta$-convergence theorems in CAT(0) spaces, Comput. Math. Appl., 56 (2008), $2572-$ 2579. 2.1, 2.12

[12] R. Espínola, P. Lorenzo, A. Nicolae, Fixed points, selections and common fixed points for nonexpansive-type mappings, J. Math. Anal. Appl., 382 (2011), 503-515. 1

[13] J. García-Falset, E. Llorens-Fuster, E. Moreno-Gálvez, Fixed point theory for multivalued generalized nonexpansive mappings, Appl. Anal. Discrete Math., 6 (2012), 265-286. 1

[14] J. García-Falset, E. Llorens-Fuster, T. Suzuki, Fixed point theory for a class of generalized nonexpansive mappings, J. Math. Anal. Appl., 375 (2011), 185-195. 1

[15] J. García-Falset, B. Sims, M. A. Smyth, The demiclosedness principle for mappings of asymptotically nonexpansive type, Houston J. Math., 158 (1996), 101-108. 3

[16] K. Goebel, S. Reich, Uniform convexity, hyperbolic geometry, and nonexpansive mappings, Monographs and Textbooks in Pure and Applied Mathematics, Marcel Dekker, Inc., New York, (1984). 2

[17] A. Kaewcharoen, B. Panyanak, Fixed point theorems for some generalized multivalued nonexpansive mappings, Nonlinear Anal., 74 (2011), 5578-5584. 1

[18] W. A. Kirk, Fixed point theorems in CAT(0) spaces and R-trees, Fixed Point Theory Appl., 4 (2004), 309-316. 2

[19] W. A. Kirk, B. Panyanak, A concept of convergence in geodesic spaces, Nonlinear Anal., 68 (2008), 3689-3696. 2, 2.9, $2.10,2.11$

[20] U. Kohlenbach, L. Leuştean, Asymptotically nonexpansive mappings in uniformly convex hyperbolic spaces, J. Eur. Math. Soc. (JEMS), 12 (2007), 71-92. 3.5

[21] T. C. Lim, Remarks on some fixed point theorems, Proc. Amer. Math. Soc., 60 (1976), 179-182. 2

[22] P.-K. Lin, K.-K. Tan, H.-K. Xu, Demiclosedness principle and asymptotic behavior for asymptotically nonexpansive mappings, Nonlinear Anal., 24 (1995), 929-946. 3 
[23] E. Llorens-Fuster, E. Moreno Gálvez, The fixed point theory for some generalized nonexpansive mappings, Abstr. Appl. Anal., 2011 (2011), 15 pages. 1, 3, 3

[24] E. Moreno Gálvez, E. Llorens-Fuster, The fixed point property for some generalized nonexpansive mappings in a nonreflexive Banach space, Fixed Point Theory, 14 (2013), 141-150. 1

[25] B. Nanjaras, B. Panyanak, W. Phuengrattana, Fixed point theorems and convergence theorems for Suzuki-generalized nonexpansive mappings in CAT(0) spaces, Nonlinear Anal. Hybrid Syst., 4 (2010), 25-31. 2, 2

[26] A. Razani, H. Salahifard, Invariant approximation for CAT(0) spaces, Nonlinear Anal., 72 (2010), 2421-2425. 1

[27] T. Shimizu, W. Takahashi, Fixed points of multivalued mappings in certain convex metric spaces, Topol. Methods Nonlinear Anal., 8 (1996), 197-203. 3.5

[28] T. Suzuki, Fixed point theorems and convergence theorems for some generalized nonexpansive mappings, J. Math. Anal. Appl., 340 (2008), 1088-1095. 1

[29] B. S. Thakur, D. Thakur, M. Postolache, A new iterative scheme for numerical reckoning fixed points of Suzuki's generalized nonexpansive mappings, Appl. Math. Comput., 275 (2016), 147-155. 4

[30] Z.-F. Zuo, Y.-N. Cui, Iterative approximations for generalized multivalued mappings in Banach spaces, Thai J. Math., 9 (2011), 333-342. 1 